\title{
Urban Migrant Labourers as Potential Source for Transfer of Antimicrobial Resistance to Rural Community
}

\author{
Debasish Chattopadhya $^{1 *}$ (D), Leimapokpam Sumitra Devi ${ }^{1}$ (D), \\ Shyam Sunder Grover ${ }^{2}$ (D) and Shobha Broor ${ }^{1}$ (D) \\ ${ }^{1}$ Department of Microbiology, SGT Medical College Hospital and Research Institute, Gurugram - 122 505, \\ Haryana, India. \\ ${ }^{2}$ Division of Microbiology, National Centre for Disease Control, Delhi - 110 054, India.
}

\begin{abstract}
The aim of the study was to investigate potential evidence for spread of antimicrobial resistance (AMR) from urban migrant labourers to labourers from local resident rural community due to sharing of common residential premises and other civic amenities. Two groups of unskilled labourers, enrolled for civil construction in a peri-urban area viz. (i) labourers having migrated from urban zone and (ii) labourers from local resident village community were compared in terms of demographic profile, history of various risk factors towards acquisition of AMR and prevalence of extended-spectrum betalactamase (ESBL), carbapenemase and New Delhi metallo-beta-lactamase type 1 (NDM-1) categories of AMR at enrolment and after one year of sharing of common residential premises with associated sanitation facilities using Escherichia coli as indicator organism. Higher percentage of urban migrant labourers were characterised by low literacy level, history of inhabitation in makeshift shelters without dedicated access to drinking water or cooking space, practice of defecation in open, episodes of illness suggestive of bacterial infections, faulty treatment seeking behaviour and intestinal carriage rate of $E$. coli with various categories of AMR compared to the non-migrant labourers from rural community. The later group showed an increase in the prevalence of carbapenem resistance with NDM-1 production during the duration of co-inhabitation with urban migrant labourers. The present study provided potential evidence for transfer of AMR by urban migrant labourers to non-migrant labourers from rural community that may serve as vehicle for further transmission of AMR to the rural community hitherto unexposed or less exposed to the problem.
\end{abstract}

Keywords: Migrant labourer, ESBL, Carbapenamase, NDM-1, Escherichia coli

*Correspondence: dchattopadhya27@gmail.com; +91 9811256697

(Received: May 19, 2020; accepted: December 09, 2020)

Citation: Chattopadhya D, Devi LS, Grover SS, Broor S. Urban Migrant Labourers as Potential Source for Transfer of Antimicrobial Resistance to Rural Community. J Pure Appl Microbiol. 2020;14(4):2371-2381. doi: 10.22207/JPAM.14.4.15

(C) The Author(s) 2020. Open Access. This article is distributed under the terms of the Creative Commons Attribution 4.0 International License which permits unrestricted use, sharing, distribution, and reproduction in any medium, provided you give appropriate credit to the original author(s) and the source, provide a link to the Creative Commons license, and indicate if changes were made. 


\section{INTRODUCTION}

Considerable concern has been expressed globally about the contribution of international human migration in the spread of antimicrobial resistance $(A M R)^{1-3}$. However, not much attention has been paid to the possible spread of AMR due to domestic migration within a country. Peri-urban area provides employment for both urban and rural community and thus serves as an important common platform for transmission of infections from urban to rural population, unexposed or less exposed to the problem ${ }^{4-6}$.

The labourer population working in urban cities frequently acquire organisms with $A M R$ as a consequence of inhabitation in poor sanitary conditions, lack of awareness about hygienic practice, inappropriate use of antibiotics due to economic constraints, poor literacy and faulty treatment seeking behaviour ${ }^{7,8}$.

The present study was carried out to assess the magnitude of AMR based on intestinal carriage rate of extended spectrum beta-lactamase (ESBL), carbapenemase and New Delhi metallo-beta-lactamase type-1 (NDM-1) in Escherichia coli as indicator organism in a group of migrant labourers from major urban cities in northern India employed as unskilled labourers for civil constructions in the peri-urban belt of North India and investigate potential evidence for transmission of AMR from the urban migrant labourers to labourers from local resident rural community employed for same job, sharing the same residential premises and civil facilities as that of urban migrant labourers during the employment period.

\section{MATERIALS AND METHODS}

The protocol of the study was approved by institutional ethics committee (SGTU/FMHS/ MICRO/341). Information sheet was provided to each of the participants and prior consent was obtained from them for the study.

\section{Study location}

The study was carried out in three clusters of temporary brick made huts (60 -70 huts per cluster) constructed to provide temporary residence to the unskilled manual labourers (as detailed below), located within $0.5 \mathrm{~km}$ distance from the campus of SGT University. Each cluster had one common toilet facility in the form of a single rectangular block of 5 brick made cubicles adjacent to each other with common walls. Each cluster was provided with one common piped water supply from the reservoir in the university campus with one common tap within residential premises of the labourers to be used by them for the purpose of drinking, cooking, washing clothes and bathing.

\section{Study population}

The study population included following two subgroups of labourers, adult males and females (mostly as family members) recruited in contractual capacity for one year as unskilled manual labourers (referred subsequently as labourers) for civil constructions at the SGT University campus located in the peri-urban belt of Haryana state in North India adjoining two major urban cities viz. Delhi and Gurgaon.

\section{The migrant labourer (ML) subgroup}

This subgroup included adults engaged in the profession as labourers in urban cities in states other than the state of Haryana for an uninterrupted period of at least 2 years preceding the present employment.

\section{The non-migrant labourers (NML) subgroup}

This subgroup included labourers from adjoining rural villages recruited at the same point of time for similar jobs as that of migrant labourers. This category of labourers, originally part time agriculture labourers, were provided residential facilities in the same clusters as that of MLs. Only those labourers who had history of uninterrupted stay in their villages during preceding two years were included in this subgroup.

\section{Study design}

The study was cross-sectional in nature carried out in two phases one year apart viz. enrolment phase (March, 2017) and follow up phase (February, 2018). Demographic and epidemiological information were collected from the participants following enrolment in 2017. Sampling for the study of AMR was carried out during first 2 weeks following enrolment and during last 2 weeks prior to the end of contract period of one year i.e. in February, 2018.

\section{Collection of information}

A pre-designed proforma was employed to collect information on age, sex, educational level and civic facilities availed by the subjects during the 6 months period prior to enrolment viz. 
type of accommodation, source of drinking water, use of toilet and space for cooking.

Information was collected regarding frequency and duration of episodes of illness during preceding two years suggestive of bacterial infections viz. chest infection, urinary tract infection, diarrhoea, skin infections like boils or furuncles and purulent discharge per ear. Information was sought on the prevalent practice of treatment seeking behaviour in these episodes of illness i.e. from hospital, registered medical practitioners, pharmacies or by self. Compliance to duration of medication prescribed by registered medical practitioners was also evaluated. History of hospitalization ( $>3$ days duration) in preceding five years was obtained from each labourer.

\section{Collection of samples}

\section{Human samples}

Morning stool samples were collected for three consecutive days during each phase from both the categories of labourers ( $\mathrm{ML}$ and $\mathrm{NML}$ ) who were provided training for self-collection of morning stool samples in sterile containers provided to them. In addition to the labourers group, sampling of morning stool was carried out for three consecutive days during each phase from 200 randomly selected age, sex and economically matched healthy residents of the same nearby villages from which the NMLs were recruited for the present study in order to collect data on the baseline prevalence of the various categories of AMR harboured by $E$. coli in the population. The collected stool samples were transported in insulated carrier box with ice packs to the microbiology laboratory, SGT Hospital within one hour.

Samples from toilet premises in the residential clusters

Soil samples around each of the three blocks of toilets used by the labourers were collected during the same two phases as that of collection of human stool samples for 10 consecutive days (except Saturday and Sunday) in each phase. Samples were collected at 20 approximately equidistant points on a line $2 \mathrm{ft}$ away from the edge of the four walls of the rectangular toilet blocks. Samples were collected at each point covering an approximate area of $10 \mathrm{~cm}$ by 10 $\mathrm{cm}$ square with five longitudinal, five latitudinal and two diagonal strokes of sterile swabs pre- moistened with nutrient broth immediately before $u^{9} e^{9}$. The points of soil sampling during the enrolment phase were identified that were subjected to resampling during the follow-up phase with reasonable accuracy.

Processing of samples for isolation of ESBL positive Escherichia coli (ESBL-EC)

Stool samples

Approximately $0.5 \mathrm{~g}$ of stool sample was suspended in $1.5 \mathrm{ml}$ of nutrient broth. From each of the suspensions, $0.1 \mathrm{ml}$ was plated on ESBL screening media viz. two MacConkey agar plates, one supplemented with $2 \mu \mathrm{g}$ of cefotaxime per $\mathrm{ml}$ (Mac-CTX) and the other one supplemented with 2 $\mu \mathrm{g}$ of ceftazidime per $\mathrm{ml}$ (Mac-CAZ) and incubated aerobically at $37^{\circ} \mathrm{C}$ for $18-24 \mathrm{~h}^{10}$. Five randomly selected lactose fermenting colonies with identical morphotype suggestive of $E$. coli on both Mac-CTX and Mac-CAZ were identified using Vitek 2 system (BioMerieux, France).

\section{Soil samples}

The swabs of soil samples collected in nutrient broth were vortexed for 2 minutes following which $0.1 \mathrm{ml}$ was plated on ESBL screening media (Mac-CTX and Mac-CAZ) and processed further as in case of stool samples.

Phenotypic confirmation of $E$. coil isolates for ESBL production

ESBL production among the $E$. coil isolates screened by the screening media was confirmed by phenotypic confirmatory tests i.e., double disc synergy test (DDST) as described earlier ${ }^{11,12}$ using two pairs of antibiotic discs, ceftazidime (30 $\mu \mathrm{g})$ and ceftazidime plus clavulanic acid ( $30 \mu \mathrm{g}$ plus $10 \mu \mathrm{g})$ discs and cefotaxime ( $30 \mu \mathrm{g})$ and cefotaxime plus clavulanic acid (30 $\mu \mathrm{g}$ plus $10 \mu \mathrm{g}$ ) discs. $K$. pneumoniae ATCC 700603 and E. coli ATCC 25922 strains were used as ESBL-positive and ESBLnegative control strains respectively.

\section{Antibiotic susceptibility testing}

Antibiotic susceptibility testing (AST) of all the confirmed ESBL-EC isolates was carried out by disc diffusion method on Mueller-Hinton agar and the AST was performed using antibiotic discs viz. ampicillin (10 $\mu \mathrm{g})$, amoxicillin-clavulanic acid $(20 / 10 \mu \mathrm{g})$, piperacillin/tazobactam (100/10 $\mu \mathrm{g})$, amikacin $(30 \mu \mathrm{g})$, gentamicin $(10 \mu \mathrm{g})$, six beta-lactam antibiotics viz. cefotaxime $(30 \mu \mathrm{g})$, ceftazidime $(30 \mu \mathrm{g})$, ceftriaxone $(30 \mu \mathrm{g})$, ceftiofur $(30 \mu \mathrm{g})$, cefepime $(30 \mu \mathrm{g})$ and aztreonam (30 
$\mu \mathrm{g})$, ciprofloxacin $(5 \mu \mathrm{g})$, co-trimoxazole $(25 \mu \mathrm{g})$, tetracycline $(10 \mu \mathrm{g})$, tigecycline $(15 \mu \mathrm{g})$, and three carbapenem group of antibiotics viz. ertapenem $(10 \mu \mathrm{g})$, meropenem $(10 \mu \mathrm{g})$ and imipenem (10 $\mu \mathrm{g})$. Results were interpreted as per CLSI guidelines (CLSI 2019) ${ }^{12}$.

Phenotypic confirmation of carbapenemase production among ESBL-EC

In-house Carba NP test was performed for phenotypic confirmation of carbapenemase production among the $E$. coli isolates (CR-EC) showing resistance to one or more carbapenems used in $\mathrm{AST}^{12}$. K. pneumoniae ATCC BAA 1705 and $E$. coli ATCC 25922 were used as positive and negative control strains respectively.

Molecular identification of $b / a_{\mathrm{TEM}}, b l a_{\mathrm{SHV}}, b l a_{\mathrm{CTX}-\mathrm{M}}$ and $b / a_{\text {NDM }}$ genes

Molecular characterization of all the

isolated E. coli strains was carried out in 2018. Phenotypically confirmed ESBL-EC were subjected to PCR assay as described earlier to detect the presence of $b / a_{\mathrm{TEM}}, b / a_{\mathrm{SHV}}$ and $b / a_{\mathrm{CTX}-\mathrm{M}}$ genes using pre-published primer sequences, viz. TEM primers (TEM forward ATGAGTATTCAACATTTCCGTG, TEM reverse TTACCAATGCTTAATCAGTGAG) amplifying 840-bp fragment, SHV primers (SHV forward ATTTGTCGCTTCTTTACTCGC, SHV reverse TTTATGGCGTTACCTTTGACC) amplifying 1051-bp fragment and CTX-M primers (CTX-M forward TTTGCGATGTGCAGTACCAGTAA, CTX-M reverse CGATATCGTTGGTGGTGCCATA) amplifying 544-bp fragment ${ }^{11,13}$.

PCR for detection of $b / a_{\mathrm{NDM}}$ was carried out for carbapenemase producing stains using the pre-published sequences viz. forward 5'-ACCGCCTGGACCGATGACCA-3' and reverse 5'-GCCAAAGTTGGGCGCGGTTG-3', which amplified $264 \mathrm{bp}$ fragment of the $b / a_{\mathrm{NDM}}$ gene $^{14}$. Gene sequencing of the amplicons was done for all the $b / a_{\mathrm{NDM}}$ genes with amplicons purified by PCR purification kit (QIAGEN, Hidden, Germany). The purified products were sequenced on ABI PRISM 3130XL sequencer using Big Dye Terminator cycle sequencing kit (Perkin Elmer). The sequences obtained were checked using BIOEDIT software followed by blast at the National Centre for Biotechnology Information website search (https://blast.ncbi.nlm.nih.gov/blast.cgi). The derived sequences were aligned with reference sequences from the database of GenBank.

\section{Statistical analysis}

The demographic and epidemiological parameters were analysed for all the subjects initially enrolled in the study while the microbiological parameters between the two phases i.e. enrolment phase and follow-up phase were compared only for those human subjects available for sampling at both the phases.

Comparison of categorical variables viz. various risk factors associated with acquisition of $A M R$ and prevalence of various categories of $A M R$ between the two subgroups as well as between the two phases of the study i.e. enrolment and follow up phases were analyzed by univariate analysis using $\chi^{2}$ test. $P$ value $<0.05$ was considered as statistically significant and it was adjusted for multiple comparisons. Fisher's exact test was used if any of the cell frequency was less than five.

\section{RESULTS}

A total of 136 and 124 labourers belonging to $M L$ and NML subgroups respectively were enrolled initially in the present study for assessment of all baseline demographic and epidemiological parameters. A total of 8 labourers from 4 families (as husbands and their wives), four each from ML and NML subgroups left the job in between and thus were not available for evaluation of changes in AMR prevalence over the follow-up period. Thus, a total of 132 and 120 subjects from ML and NML subgroups respectively were considered for comparison of AMR prevalence between enrolment and followup phase.

The labourers in the ML subgroup were in the profession as unskilled labourers for a median duration of 5.4 years $(95 \% \mathrm{Cl} 3.2-8.6)$ in three cities viz. Delhi, Jaipur and Gurgaon of north India with uninterrupted stay in one of the three cities for at least 6 months (mean duration $9 \pm 1.5$ months) prior to enrolment in the present study.

A significantly higher proportion of subjects in ML subgroup had no formal education or had education only upto primary $\left(4^{\text {th }}\right.$ standard) level compared to NML subgroup (81 out of 136 i.e. $59.6 \%$ with no formal education and 48 out of 136 i.e. $35.3 \%$ with education upto primary level in ML subgroup versus 14 out of out of 124 i.e. $11.3 \%$ with no formal education and 13 out of 124 i.e. $10.5 \%$ with education upto primary level in NML 
subgroup; $P<0.01$ for both levels of education, data not shown in the table). Higher proportion of the ML subgroup had resided in make-shift road side shelters covered with polythene sheets before enrolment while the labourers belonging to NML subgroup had their stay in stable residences (brick made) registered in their names. While the practice of defecation in the open was prevalent among the labourers in both the subgroups, the proportion was significantly higher in the ML subgroup with majority resorting to the practice of defecating in the open, mostly on the edges of open drainage lines or boundary walls while higher proportion of subjects in the NML subgroup reported to have had the facility of dedicated toilets. Most of the labourers in the ML subgroup revealed history of using public roadside taps for drinking water and had to cook in open space adjacent to their shelters compared to the labourers in NML subgroup who enjoyed the privilege of having dedicated piped water supply for drinking and self-owned closed space for cooking (Table1).

Episodes of illness prior to enrolment viz. chest infection and diarrhoea were significantly more frequent in the $\mathrm{ML}$ subgroup compared to NML subgroup although none of the episodes required hospitalisation or parenteral medication in either of the two subgroups (data not shown in table). However, treatment seeking behaviour for these episodes was different between the subgroups. While higher proportion of illness in the $M L$ subgroup were attended by registered medical practitioners compared to NML subgroup, the same attended by pharmacists was more common in the later subgroup compared to the former. Practice of self-medication was more prevalent in the ML subgroup compared to NML subgroup while left over medicines were used in small percentages of illness by both the subgroups. Non-completion of the duration of treatment recommended by registered medical practitioners was more commonly reported by the ML subgroup of labourers compared to NML subgroup (Table 2).

The fecal carriage rate of ESBL-EC was significantly higher in the ML subgroup compared to those belonging to NML subgroup at the time of enrolment for the employment. However, on follow-up, there was no significant difference in the fecal carriage rate of ESBL-EC between both the subgroups due to decrease in their carriage rate in the former subgroup with concomitant increase in similar carriage rate in the later subgroup during the follow-up. CTX-M was the predominant molecular variety of ESBL detected among the ESBL-EC isolates from both $\mathrm{ML}$ and NML subgroups. The trend in the resistance rates of carbapenemase and NDM-1 variety of AMR during the follow-up period was similar to that observed in case of ESBL-EC positivity i.e. decline in rates in the $M L$ subgroup with increase in the NML subgroup, during the follow-up period. On relative terms, the increase in the prevalence of NDM-1 during the follow-up period was more apparent in the NML subgroup when the same subgroup, detected to be free from carriage of NDM- 1 at enrolment, acquired the same category of resistance in $8.7 \%$ of subjects during follow-up. There was significant increase in the isolation rates

Table 1. Comparison of risk factors towards acquisition of AMR between migrant labourers $(\mathrm{ML})$ and non-migrant labourers (NML)

\begin{tabular}{|c|c|c|c|}
\hline \multicolumn{2}{|c|}{ Characteristics of the study population } & $\begin{array}{l}\mathrm{ML}(\mathrm{n}=136) \\
\text { No. }(\%)\end{array}$ & $\begin{array}{l}\text { NML }(n=124) \\
\text { No. }(\%)\end{array}$ \\
\hline Accommodation in make & shelters* & $82(60.3)^{1}$ & $2(1.6)$ \\
\hline Defecation practice in op & & $134(98.5)^{a, 1}$ & $84(67.7)^{b}$ \\
\hline & Separate piped supply & $2(1.5)$ & $70(56.5)^{2}$ \\
\hline \multirow[t]{3}{*}{ Source of drinking water } & Public tap & $132(97)^{1}$ & $40(32.6)$ \\
\hline & Tube well & $2(1.5)$ & $10(8.0)^{2}$ \\
\hline & Brick well & $0(0)$ & $4(3.2)$ \\
\hline Cooking in open space & & $134(98.5)^{1}$ & $2(1.6)$ \\
\hline
\end{tabular}

* Mostly polythene sheet tents in open space near construction site

$a=$ Open space, adjacent to boundary walls, open drainages; $b=$ Agricultural fields

Statistical comparisons: $1=\mathrm{ML}>\mathrm{NML}(\mathrm{p}<0.01) ; 2=\mathrm{NML}>\mathrm{ML}(\mathrm{p}<0.01)$ 
of ESBL, carbapenemase and NDM-1 producing $E$. coli from the soil samples of toilet premises during the follow-up period (Table 3). The prevalence of ESBL-EC and ESBL-CR at enrolment in the NML subgroup was comparable to that of healthy nonlabour rural community in their native villages with prevalence of ESBL-EC and ESBL-CR as $22.5 \%$ (45 out of 200) and 2.5\% (5 out of 200) respectively at enrolment and $23.5 \%$ (47 out of 200 ) and $3 \%$ (6 out of 200) respectively at follow-up without any statistical difference between the two phases (data not shown in table). No NDM-1 could be detected in enrolment or follow-up samples from the healthy non-labour rural population.

Antibiotic sensitivity pattern of the ESBL-EC isolates from the two subgroups showed comparably high degree of co-resistance to the beta-lactam group of antibiotics except newer beta-lactams viz. cefepime and aztreonam in both the subgroups. Resistance to ceftiofur, a third-generation cephalosporin, known to be used mainly for livestock ailment rather than human use, was recorded only among the $E$. coli isolates from NML subgroup at enrolment without any positivity detected in ML subgroup at the same point. Moderate degree of co-resistance was also recorded for carbapenem group of antibiotics in both subgroups although prevalence was higher in $\mathrm{ML}$ subgroup compared to NML subgroup. Moderate degree of co-resistance was also noted for three antibiotics other than beta-lactam and carbapenem groups i.e. fluoroquinolone (ciprofloxacin), co-trimoxazole and tetracycline tested at enrolment with comparable prevalence between the two subgroups. On follow-up, significant change in prevalence of co-resistance were recorded in both the subgroups for those antibiotics with difference in prevalence recorded at enrolment. Prevalence of resistance were found to decrease for all the three carbapenem group of antibiotics tested in the ML subgroup with concomitant increase in the NML subgroup during the follow-up period. On the other hand, the $\mathrm{ML}$ subgroup was found to acquire resistance to ceftiofur during the follow-up period with concomitant reduction on follow-up in the NML subgroup for this antibiotic (Table 4).

Table 2. Magnitude of selected illness suspected to be of bacterial origin requiring intake of medicine and treatment seeking behaviour among the labourers

\begin{tabular}{|c|c|c|c|c|}
\hline \multirow[t]{2}{*}{ Characteristics } & & \multicolumn{2}{|c|}{ Study population } & \multirow[t]{2}{*}{ P-value } \\
\hline & & $\begin{array}{c}M L \\
(n=136)\end{array}$ & $\begin{array}{c}\text { NML } \\
(n=124)\end{array}$ & \\
\hline \multirow{4}{*}{$\begin{array}{l}\text { Incidence of SBI requiring } \\
\text { intake of medication (episodes } \\
\text { per person year) }\end{array}$} & Chest infection & 0.46 & 0.18 & $<0.001^{1}$ \\
\hline & Urinary tract infection & 0.31 & 0.29 & NS (0.8) \\
\hline & Diarrhoea & 0.24 & 0.1 & 0.0041 \\
\hline & $\begin{array}{l}\text { Suppurative infections } \\
\text { (boils, ear discharge, eye } \\
\text { infection) }\end{array}$ & 0.03 & 0.02 & NS (0.5) \\
\hline \multirow{6}{*}{$\begin{array}{l}\text { Treatment seeking behaviour, } \\
\text { No(\%) out of total SBI episodes }\end{array}$} & From hospital & $12(8.5)$ & $8(6.5)$ & NS (0.5) \\
\hline & From RMP & $32(22.7)^{1}$ & $11(8.9)$ & $0.001^{1}$ \\
\hline & From pharmacist & $54(39.7)$ & $87(70.2)^{2}$ & $<0.001^{2}$ \\
\hline & Self-medication & $26(19.1)^{1}$ & $7(5.6)$ & $0.001^{1}$ \\
\hline & Use of stored medicine & $12(8.8)$ & $11(8.9)$ & NS (0.9) \\
\hline & $\begin{array}{l}\text { Completion of } \\
\text { recommended duration } \\
\text { of treatment* }\end{array}$ & $5(15.6)$ & $6(54.5)^{2}$ & NS (0.6) \\
\hline
\end{tabular}

SBI = Suspected bacterial infections; RMP = Registered Medical Practitioner

*Calculated out of the episodes attended by registered medical practitioners.

Note: Only two subjects in migrant labourers subgroup and one subject in non-migrant labourers subgroup had single episode of hospitalization in preceding 5 years

Statistical comparisons: $1=\mathrm{ML}>\mathrm{NML}(\mathrm{p}<0.05) ; 2=\mathrm{NML}>\mathrm{ML}(\mathrm{p}<0.05) ; \mathrm{NS}=$ Not significant

Journal of Pure and Applied Microbiology 


\section{DISCUSSION}

There is no internationally recognized definition of migrants. According to the International Federation of Red Cross and Red Crescent Societies' policy on migration, migrants are described as people who leave or flee their places of habitual residence to go to a new place, across international borders or within their own state, to seek better or safer perspectives and thus includes labour migrants, stateless migrants, migrants deemed irregular by public authorities, migrants displaced within their own country, refugees and asylum-seekers ${ }^{6}$. While the focus has mainly been directed so far towards AMR hazards associated with international migration, problem of internal migration within a country has been underestimated in this regard. According to a report by United Nations Development Programme (UNDP), the number of those who moved across the major zonal demarcations within their countries was nearly four times larger (740 million) than those who moved internationally (214 million) ${ }^{15}$. The National Sample Survey Organisation (NSSO) of India estimated that in 2007-08 there were 326 million internal migrants (28.5\% of the population) $)^{16}$. In India about $59 \%$ of growth in the urban population is due to natural increase with rural to urban migration contributing to about $21 \%$ of increase ${ }^{17}$. Migration between states in India is mostly an outcome of economic need, poor people living in rural India frequently migrate to urban cities in search of employment ${ }^{4}$. Migration of labourers in search of jobs within short period following birth of their children coupled with frequent change of workplace within or outside the state may explain lack of education beyond primary level among majority of labourers in the ML subgroup. In a nationwide study undertaken in 13 Indian cities on migrant labourers, the overall analysis showed $43.4 \%$ of the migrants reportedly living in non-notified slums and $11.7 \%$ in dwellings at work sites while the corresponding figures for the subsection of those in the city of Delhi were found be $48.5 \%$ and $42.7 \%$ respectively reflecting the rapid expansion of civil infrastructures in the city. In the same study only $4.7 \%$ of migrant labourers in the city of Delhi were reported to be living in open spaces including footpaths, market place, under the bridges etc. This is in contrast to our study that demonstrated more than $60 \%$ of the migrant labourers living in open spaces with polythene sheet covered shelters. This could be due to the difference in the nature of labour jobs for which the labourers were recruited since the former study subjects were surveyed from building construction sites that usually provide closed brick shelters within the building under

Table 3. Prevalence of fecal carriage of ESBL, types of ESBL, carbapenemase and NDM-1 types of AMR in E. coli in human subjects and in soil samples from toilet premises of labourers

\begin{tabular}{|c|c|c|c|c|c|c|}
\hline \multirow{3}{*}{ Type of resistance } & \multirow{2}{*}{\multicolumn{4}{|c|}{ Human subjects }} & \multirow{2}{*}{\multicolumn{2}{|c|}{$\begin{array}{l}\text { Toilet premises } \\
\qquad(n=600)\end{array}$}} \\
\hline & & & & & & \\
\hline & $\begin{array}{c}\text { En } \\
\text { No. (\%) }\end{array}$ & $\begin{array}{c}\mathrm{Fu} \\
\text { No. (\%) }\end{array}$ & $\begin{array}{c}\text { En } \\
\text { No. (\%) }\end{array}$ & $\begin{array}{c}\mathrm{Fu} \\
\text { No. (\%) }\end{array}$ & $\begin{array}{c}\text { En } \\
\text { No. (\%) }\end{array}$ & $\begin{array}{c}\mathrm{Fu} \\
\text { No. (\%) }\end{array}$ \\
\hline ESBL & $63(47.7)$ & $45(34.1)^{\#}$ & $28(23.3)$ & $46(38.3)^{@}$ & $72(12)$ & $128(21.3)^{@}$ \\
\hline CTX-M ESBL alone* & $45(71.4)$ & $34(75.6)$ & $23(82.2)$ & $39(84.8)$ & 59 (81.9) & $101(77.7)$ \\
\hline $\begin{array}{l}\text { CTX-M with other } \\
\text { ESBL genes* }\end{array}$ & $7(11.1)$ & $4(8.8)$ & $3(10.7)$ & 5 (10.9) & $5(6.9)$ & $17(13.1)$ \\
\hline Other ESBL genes * & $11(17.5)$ & $7(15.6)$ & $2(7.1)$ & $2(4.3)$ & $8(11.1)$ & $7(5.4)$ \\
\hline Carbapenamase* & 11 (17.5) & $4(8.9)^{\#}$ & $1(3.6)$ & $6(13)^{@}$ & 1 (1.4) & $8(6.3)^{@}$ \\
\hline NDM-1* & $8(12.7)$ & $3(6.7)^{\#}$ & 0 & $4(8.7)$ & 0 & $3(2.3)$ \\
\hline
\end{tabular}

$\mathrm{ML}=$ Migrant labourers; NML= Non-migrant labourers; $\mathrm{En}=$ Enrolment; $\mathrm{Fu}=$ Follow-up

*Calculated as no (\%) of the total ESBL positive isolates.

" Significant decrease in prevalence on follow-up $(\mathrm{P}<0.05)$ compared to enrolment in the same subgroup.

${ }^{\circledR}$ Significant increase in prevalence on follow-up $(\mathrm{P}<0.05)$ compared to enrolment in the same subgroup. 
construction till the construction was completed. The migrant labourers at construction sites in the country reportedly have access to public tap as source of potable water and majority of them are reported to be practicing defecation in open which is similar to our observation ${ }^{8}$. Public health related facilities such as provision of safe drinking water, improved sewage disposal and housing have been considered to be the basic pre-requisites for containing the incidence of communicable diseases of major public health importance not only in developing countries ${ }^{18,19}$ but also in a developed country ${ }^{7}$. Significant differences in availability of these basic facilities could explain higher incidence of episodes of illness suspected to be of bacterial origin in ML subgroup compared to NML subgroup in the present study.

Shortage of available registered medical practitioners in rural India is well recognised ${ }^{20}$ that could be the reason for the majority of the rural population resorting to help from pharmacies for medication. Self-medication is a globally recognized concern with the prevalence range in India and other developing countries reported to be as high as $78 \%-92.8 \%{ }^{21-23}$, although limited studies have focussed on antibiotic related selfmedication. One comparative study on antibiotic related self-medication between urban and rural population within same zone in India has shown the prevalence of such practice to be more common in the former sector compared to later, although the study was based on survey conducted in pharmacy outlet ${ }^{24}$. As opposed to this pharmacy outlet-based study that may not be representative of the problem in the general community, the present study on antibiotic usage was based on survey in two distinct subpopulations from urban and rural community. Considering the overall low literacy rate in the two study subpopulations to clearly recognise medications as antibiotics and non-availability of prescriptions, the present study relied on usage of drugs in ailments suggestive of bacterial infection as correlate of antibiotic usage which showed self-medication of probable

Table 4. Antibiotic resistance profile of ESBL-EC isolated from faecal samples of human study subjects and soil samples from toilet premises of the labourers

\begin{tabular}{|c|c|c|c|c|c|c|}
\hline \multirow{2}{*}{$\begin{array}{l}\text { Antibiotics } \\
\text { (Disc potency) }\end{array}$} & \multicolumn{2}{|c|}{ ML } & \multicolumn{2}{|c|}{ NML } & \multicolumn{2}{|c|}{ Toilet premises } \\
\hline & $\begin{array}{c}\text { En } \\
(n=63) \\
\text { No (\%) }\end{array}$ & $\begin{array}{c}\mathrm{Fu} \\
(n=45) \\
\text { No (\%) }\end{array}$ & $\begin{array}{c}\text { En } \\
(n=28) \\
\text { No (\%) }\end{array}$ & $\begin{array}{c}\mathrm{Fu} \\
(\mathrm{n}=46) \\
\text { No (\%) }\end{array}$ & $\begin{array}{c}\text { En } \\
(n=72) \\
\text { No (\%) }\end{array}$ & $\begin{array}{c}\mathrm{Fu} \\
(\mathrm{n}=128) \\
\mathrm{No}(\%)\end{array}$ \\
\hline AMC $(20 / 10 \mu \mathrm{g})$ & 22 (34.9) & $14(31.1)$ & 11(39.3) & 20 (43.5) & $18(25)$ & $37(28.5)$ \\
\hline 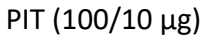 & 5 (7.9) & $2(4.4)^{\#}$ & $2(7.1)$ & 4 (8.7) & 0 & $2(1.5)$ \\
\hline AK $(30 \mu \mathrm{g})$ & $3(4.8)$ & $2(4.4)$ & 0 & $2(4.3)$ & 0 & 0 \\
\hline GEN (10 $\mu \mathrm{g})$ & $5(7.9)$ & $4(8.9)$ & $2(7.1)$ & 5 (10.9) & $2(2.8)$ & $6(4.6)$ \\
\hline CAZ $(30 \mu \mathrm{g})$ & $63(100)$ & $43(95.6)$ & $27(96.4)$ & $46(100)$ & $67(93.1)$ & $124(95.4)$ \\
\hline EFT (30 $\mu \mathrm{g})$ & 0 & $8(17.8)^{@}$ & $9(32.1)$ & $6(13)^{\#}$ & $4(5.5)$ & $17(13.1)^{\#}$ \\
\hline 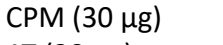 & $24(38.1)$ & $15(33.3)$ & $7(25)$ & $20(43.5)$ & $3(4.2)$ & $9(6.9)$ \\
\hline AT $(30 \mu \mathrm{g})$ & $63(100)$ & 45 (100) & 27 (96.4) & 43 (97.8) & 69 (95.8) & $128(98.5)$ \\
\hline ETP $(10 \mu \mathrm{g})$ & $13(20.6)$ & $6(13.3)^{\#}$ & $2(7.1)$ & $6(13)^{@}$ & $2(2.8)$ & $11(8.6)^{@}$ \\
\hline IMP (10 ㅆg) & $15(23.8)$ & $8(17.8)^{\#}$ & $2(7.1)$ & $9{(19.6)^{@}}^{@}$ & $4(5.6)$ & $12(9.4)^{@}$ \\
\hline MRP (10 $\mu \mathrm{g})$ & $14(22.2)$ & $6(13.3)^{\#}$ & $3(10.7)$ & $7(15.2)^{@}$ & $2(2.8)$ & $11(8.6)^{@}$ \\
\hline CIP $(5 \mu \mathrm{g})$ & $28(44.4)$ & $22(48.9)$ & $11(39.3)$ & $16(34.8)$ & $8(11.1)$ & $20(15.6)$ \\
\hline СОT $(25 \mu \mathrm{g})$ & $26(41.3)$ & $18(35.6)$ & 11(39.2) & $19(41.3)$ & 9 (12.5) & 14(10.9) \\
\hline 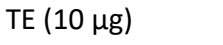 & 22 (34.9) & $13(28.9)$ & 12 (42.9) & $20(43.5)$ & $10(13.9)$ & $16(12.5)$ \\
\hline
\end{tabular}

$\mathrm{ML}=$ Migrant labourers; NML= Non-migrant labourers; En = Enrolment; Fu = Follow-up; $\mathrm{AMC}=\mathrm{Amoxyclav} ; \mathrm{PIT}=\mathrm{Piperacillin} /$ Tazobactam; AK= Amikacin; GEN= Gentamicin; CAZ= Ceftazidime; EFT= Ceftiofur; $C P M=$ Cefepime; AT= Aztreonam; ETP= Ertapenem; IPM= Imipenem; $\mathrm{MRP}=$ Meropenem; $\mathrm{CIP}=$ Ciprofloxacin; $\mathrm{COT}=$ Co-trimoxazole; $\mathrm{TE}=\mathrm{Tetracycline}$ Statistical comparisons:

"Significant decrease on follow-up $(\mathrm{P}<0.05)$ compared to enrolment in the same subgroup.

@Significant increase on follow-up $(P<0.05)$ compared to enrolment in the same subgroup.

Note: All the isolates were resistant to ampicillin, ceftriaxone and cefotaxime and sensitive to tigecycline 
antibiotics to be more prevalent in $\mathrm{ML}$ subgroup compared to NML subgroup similar to that observed in pharmacy based survey.

While there are few reports on the intestinal carriage rate of ESBL mediated AMR among healthy rural community in India, ranging from $15.4 \%$ to $33.8 \%{ }^{25,26}$, there is hardly any information available on carriage rate of carbapenem and NDM-1 mediated AMR in the healthy rural community, most of the reports originating from studies on hospitalized patients from rural community ${ }^{14}$. Laxminarayan and Choudhary reported that non-prescription sales of carbapenems in India is among the highest in the world contributing to growing problem of carbapenem resistance 27 . To the best of our knowledge, there is very little information available on the carriage rate of carbapenemase and NDM-1 mediated resistance in asymptomatic rural community. High resistance rate among NML subgroup to ceftiofur, a third-generation cephalosporins mainly used for ailments in the livestock population ${ }^{28}$ could be due to their association with livestock care where prevalence of resistance to this antibiotic has been reported to be as high as $>50 \%{ }^{29}$. Such possibility may be of serious concern since resistance to ceftiofur and cephalosporins e.g. ceftriaxone are shared by common genes viz bla ${ }_{\mathrm{CMY}-2}$ and bla $a_{\text {CTX-M }}{ }^{30}$ and reported emergence of resistance to third generation cephalosporins of human importance in $E$. coli after ceftiofur use ${ }^{31}$. Due to the cheaper cost of some antibiotics, especially ciprofloxacin, co-trimoxazole and tetracycline ${ }^{32}$, these antibiotics are indiscriminately used in India by population with low socioeconomic status explaining moderate resistance to these antibiotics among the $E$. coli isolates obtained from both the subgroups at enrolment ${ }^{32}$. A study on rural community from central India reported multidrug resistant $E$. coli with high resistance to these antibiotics ranging from $28-69 \%{ }^{26}$.

The present study demonstrated comparably high prevalence of co-resistance to common beta-lactam group of antibiotics in ESBL-EC isolated at enrolment from both the subgroups, a finding that was expected since the isolates selected for study of co-resistance were the ones screened as ESBL positives (vide materials and methods). While no change in prevalence of co-resistance to beta-lactam group of antibiotics was demonstrable in both the subgroups on follow-up, a decline in the prevalence of coresistance to carbapenem group of antibiotics could be observed during the follow-up in the $\mathrm{ML}$ subgroup with concomitant increase in prevalence of similar categories of resistance in NML subgroup during the same period. In absence of history of hospitalisation or parenteral therapy in the study population such resistance to carbapenems could be due to colonisation of carbapenem resistant organisms acquired through contaminated food, water and environment rather than any antibiotic pressure $^{33}$. This is further supported by higher prevalence of ESBL and carbapenem mediated resistance observed in the $\mathrm{ML}$ subgroup that was characterised by unhygienic living conditions compared to NML subgroup. Resistance in Enterobacteriaceae group of bacteria acquired through international travel are mostly reported to disappear by six months on return to home country $^{34,35}$. In a longitudinal study with monthly monitoring of a cohort of 245 travellers with travelacquired multi-drug resistant Enterobacteriaceae, the resistant strains were found to persist in only $33 \%$ after 4 weeks and in only $5 \%$ after 6 months $\mathrm{s}^{35}$. Thus it may be assumed that reduction in prevalence of ESBL and carbapenem resistance in the ML subgroup was due to shedding of the organisms at a rate higher relative to the rate of new acquisition while the increase in the NML subgroup was due to higher rate of acquisition of same organisms relative to their shedding in the process of sharing of environment e.g. toilets, washing and bathing area. This was further substantiated by the finding that prevalence of resistance to beta-lactam and carbapenem group of antimicrobials at enrolment in the NML subgroup was comparable to that of healthy rural community in their native villages. In the study by Haverkate et al. the estimated probability of transfer of ESBL producing Enterobacteriaceae from an index patient to the household contact was $67 \%$ with person-to-person transmission occurring at a rate of $0.0053 /$ person/day and decolonization at $0.0026 /$ person/day for index patients ${ }^{36}$.

Concomitant increase in the prevalence of co-resistance to carbapenem group of antibiotics among ESBL positive isolates from soil 
in toilet premises during the follow-up period, commensurate with the observed increase in carbapenem resistance suggest that contaminated soil environment in toilet premises could be a potential source for acquisition of AMR by the NML subgroup of labourers. Increase in the prevalence of ESBL, carbapenemase and NDM-1 varieties of AMR among $E$. coli in the soil samples from toilet premises during the follow-up period indicate that toilet premises could be a potentially conducive platform for acquisition of these varieties of AMR. Acquisition of high rate of AMR by the labourers recruited from local villages is a matter of concern keeping in mind possible carriage of such resistance by them to their native villages on their return from employment and consequent spread to the local rural community hitherto unexposed or minimally exposed to the problem.

\section{ACKNOWLEDGMENTS}

NONE.

\section{CONFLICT OF INTEREST}

The authors declare that there is no conflict of interest.

\section{AUTHORS' CONTRIBUTION}

DC contributed to the study conception and designing the protocol of the study, carried out data analysis and contributed in manuscript writing; LSD contributed in samples collection, data collection, conducting laboratory work and manuscript writing; SSG contributed in data collection and conducting laboratory work; SB supervised the overall work and undertook revision of the manuscript. All authors read and approved the final manuscript.

\section{FUNDING}

NONE.

\section{DATA AVAILABILITY}

GenBank accession numbers for bla are given below: ML subgroup (Enrolment): NPS_1 JX292120.1, NPS_2 JX292121.1, NPS-3 JX292122.1, NPS_4 JX292123.1, NPS_5 KJ410404.1, NPS_6 KJ410405.1, NPS_7 KJ410406.1, NPS_8 KU158096.1 ML subgroup (Follow-up): NPS_9 KU158097.1, NPS_10 KU158098.1, NPS_11 KU158099.1

NML subgroup (Follow up): NPS_12
KU158100.1, NPS_13 KU158101.1, NPS_14 KU158102.1, NPS_15 KU158103.1

Toilet premises (Follow-up): MN433632, MN433631, MN433630

\section{ETHICS STATEMENT}

This study was approved by both independent institutional research and ethical committees of SGT University, approval no. SGTU/ FMHS/MICRO/341.

\section{REFERENCES}

1. Tangden T, Cars O, Melhus A, Lowdin E. Foreign travel is a major risk factor for colonization with Escherichia coli producing CTX-M-type extendedspectrum $\beta$-lactamases: a prospective study with Swedish volunteers. Antimicrob Agents Chemother. 2010;54(9):3564-3568. doi: 10.1128/AAC.00220-10

2. Nordmann P, Naas T, Poirel L. Global spread of carbapenemase producing Enterobacteriaceae. Emerg Infect Dis. 2011;17(10):1791-1798. doi: 10.3201/ eid1710.110655

3. van der Bij AK and Pitout JDD. The role of international travel in the world wide spread of multi-resistant Enterobacteriaceae. J Antimicrob Chemother. 2012;67(9):2090-2100. doi: 10.1093/jac/dks214

4. Ashok S, Thomas PN. A study on issues of interstate migrant labourers in India. Int J Sci Eng Res. 2014;5(7):91-94.

5. Amrith SS. Migration and health in southeast Asian history. Lancet. 2014;384(9954):1569-1570. doi: 10.1016/S0140-6736(14)61976-0

6. International Federation of Red Cross and Red Crescent Societies' publication. Migration in South East Asia. 2015.

7. Nomamiukor BO, Hornrt C, Kirby A, Hughes J. Living conditions are associated with increased antibiotic resistance in community isolates of Escherichia coli. J Antimicrob Chemother. 2015;70(11):3154-3158. doi: 10.1093/jac/dkv229

8. Babu BV, Kusuma YS, Sivakami M, et al. Living conditions of internal labour migrants: a nationwide study in 13 Indian cities. Int J Migr Border Stud. 2017;3(4):328-351. doi: 10.1504/IJMBS.2017.086963

9. Freeman JC, Nimmo J, Gregory E, et al. Predictors of hospital surface contamination with ESBL-producing Escherichia coli and Klebsiella pneumoniae: patient and organism factors. Antimicrob Res Infect Cont. 2014;3:5. doi: 10.1186/2047-2994-3-5

10. Luvsansharav UO, Hirai I, Nakata A, et al. Prevalence of and risk factors associated with faecal carriage of CTX-M b-lactamase-producing Enterobacteriaceae in rural Thai communities. J Antimicrob Chemother. 2012;67(7):1769-1774. doi: 10.1093/jac/dks118

11. Devi LS, Broor S, Chakravarti A, Chattopadhya D. Livestock manure as potential reservoir of CTX-M type extended-spectrum $\beta$-lactamase producing Escherichia coli and Klebsiella pneumoniae associated with carbapenemase production. J Pure Appl Microbiol. 
2020;14(1):171-181. doi: 10.22207/JPAM.14.1.18

12. Clinical Laboratory Standard Institute (CLSI). Performance standards for antimicrobial tusceptibility Testing; 29th Informational Supplement. M100-S27, Wayne, Pennsylvania, USA. 2019.

13. Sidjabat HE, Paterson DL, Adams-Haduch JM, et al. Molecular Epidemiology of CTX-M-Producing Escherichia coli Isolates at a Tertiary Medical Centre in Western Pennsylvania. Antimicrob Agents Chemother. 2009;53(11):4733-4739. doi: 10.1128/AAC.00533-09

14. Devi LS, Grover SS, Khare S, Broor S, Chattopadhya D. Carbapenemase and NDM-1 production by Escherichia coli and Klebsiella pneumoniae from patients belonging to a rural community in North India hospitalized with community- acquired infections. I Commun Dis. 2018;50:5-10. doi: 10.24321/0019.5138.201808

15. United Nations Development Programme, Human development Report. Overcoming Barriers: Human mobility and development, UNDP, New York. (http:// hdr.undp.en/media/HDR_2009_EN- (accessed 28.02.2016). 2009.

16. National Sample Survey Organization, Government of India Publication. Migration in India $(2007,2008)$, 64th Round, National sample survey office, Ministry of Statistics Programme Implementation. Government of India, New Delhi. 2010.

17. Ministry of urban development and poverty alleviation, Government of India Report. Report of high-powered expert committee on urban infrastructure and services, Government of India, New Delhi. 2011.

18. Kulshrestha M, Mittal AK. Diseases associated with poor water and sanitation: hazards, prevention and solutions. Rev Environ Health. 2003;8(1):33-50. doi: 10.1515/REVEH.2003.18.1.33

19. Gushulak BD, MacPherson DW. The basic principles of migration health: population mobility and gaps in disease prevalence. Emerg Themes Epidemiol. 2006; 3:3. doi: $10.1186 / 1742-7622-3-3$

20. Sharma DC. India still struggles with rural doctor shortages. Lancet. 2015;386(10011):2381-2382. doi: 10.1016/S0140-6736(15)01231-3

21. Afridi MI, Rasool G, Rabia T, Shaheen M, Siddiqullah, Shujauddin M. Prevalence and pattern of selfmedication in Karachi: A community survey. Pak J Med Sci. 2015;31(5):1241-1245. doi: 10.12669/ pjms.315.8216

22. Oshikoya K, Senbanjo I, Njokanma O. Self-medication for infants with colic in Lagos, Nigeria. BMC Pediatrics. 2009;9:9.

23. Kumar N, Kanchan T, Unnikrishnan B, et al. Perceptions and practices of self-medication among medical students in coastal south India. PLOS ONE. 2013;8(8):e72247. doi: 10.1371/journal.pone.0072247

24. Dineshkumar B, Raghuram TC, Radhaiah G, Krishnaswamy K. Profile of drug use in urban and rural India. Pharmacoeconomics. 1995;7(4):332-346. doi: 10.2165/00019053-199507040-00007

25. Indernath S, Priyadharsini RI, Manikkanan M, Babu SV. Prevalence and phenotypic characterization of ESBL producing E. coli and Klebsiella among the fecal isolates of normal population. Indian J Microbiol Res. 2018;5(1):52-56. doi: 10.18231/2394-5478.2018.0010
26. Pathak A, Chandran SP, Mahadik K, Macaden R, Lundborg CS. Frequency and factors associated with carriage of multi-drug resistant commensal Escherichia coli among women attending antenatal clinics in Central India. BMC Infect Dis. 2013;13:199. doi: 10.1186/1471-2334-13-199

27. Laxminarayan $R$, Choudhary RR. Antibiotic resistance in India: drivers and opportunities for action. PLOS Med. 2016;13(3):e1001974. doi: 10.1371/journal. pmed.1001974

28. Hornish RE, Kotarski SF. Cephalosporins in veterinary medicine- Ceftiofur use in food animals. Curr Top Med Chem. 2002;2(7):717-731. doi: 10.2174/1568026023393679

29. Arya G, Roy A, Choudhary V, Yadav MM, Joshi CG. Serogroups, atypical biochemical characters, colicinogeny and antibiotic resistance pattern of Shiga toxin-producing Escherichia coli isolated from diarrhoeic calves in Gujarat, India. Zoonoses Public Health. 2008;55:89-98. doi: 10.1111/j.18632378.2007.01093.x

30. Mukerji S, O'Dea M, Barton M, Kirkwood R, Lee $\mathrm{T}$, Abraham S. Development and transmission of antimicrobial resistance among gram negative bacteria in animals and their public health impact. Essays Biochem. 2017;61(1):23-35. doi: 10.1042/ EBC20160055

31. Sato T, Okubo T, Usui M, Yokota S-I, Izumiyama $\mathrm{S}$, Tamura Y. Association of Veterinary Third-Generation Cephalosporin Use with the Risk of Emergence of Extended-Spectrum-Cephalosporin Resistance in Escherichia coli from Dairy Cattle in Japan. PLoS ONE. 2014;9(4):e96101. doi: 10.1371/journal. pone. 0096101

32. Chandy SJ, Thomas K, Mathai E, Antonisamy B, Holloway KA, Lundborg CS. Patterns of antibiotic use in the community and challenges of antibiotic surveillance in a lower-middle-income country setting: a repeated cross-sectional study in Vellore, South India. J Antimicrob Chemother. 2013;68(1):229-236. doi: $10.1093 / \mathrm{jac} / \mathrm{dks} 355$

33. Codsje FS, Donkor ES. Carbapenem resistance: a review. Med Sci (Basel). 2018;6(1):1. doi: 10.3390/ medsci6010001

34. Ruppe E, Armand-Lefevre L, Estellat C, et al. High rate of acquisition but short duration of carriage of multidrug resistant Enterobacteriaceae after travel to the tropics. Clin Infect Dis. 2015;61:593-600. doi: 10.1093/ cid/civ333

35. Lubbert C, Straube L, Stein C, et al. Colonization with extended-spectrum beta-lactanase -producing and carbapenemase -producing Enterobacteriaceae in international travellers returning to Germany. Int J Med Microbiol. 2015;305(1):148-156. doi: 10.1016/j. ijmm.2014.12.001

36. Haverkate MR, Platteel TN, Fluit AC, et al. Quantifying within house-hold transmission of extended spectrum beta-lactamase-producing bacteria. Clin Microbiol Infect. 2017;23(1):46.e1-46.e7. doi: 10.1016/j. cmi.2016.08.021 